\title{
СОВРЕМЕННОЕ СОСТОЯНИЕ ИЗУЧЕННОСТИ БУРЕНИЯ НАПРАВЛЕННЫХ И МНОГОЗАБОЙНЫХ СКВАЖИН С РАЗДЕЛЬНОЙ ЭКСПЛУАТАЦИЕЙ ОДНОВРЕМЕННО НЕСКОЛЬКИХ ГОРИЗОНТОВ (ЗАРУБЕЖНЫЙ ОПЫТ)
}

\author{
Деряев Аннагулы Реджепович \\ кандидат технических наук, научный сотрудник \\ Научно-исследовательский институт природного газа \\ ГК «Туркменгаз»
}

\begin{abstract}
Аннотация: Экономический эффект от внедрения технологии одновременно-раздельной эксплуатации бурением направленных скважин выражается за счет уменьшения затрат на бурение дополнительных скважин, а также дает возможность сокращения срока окупаемости вложений и снижения операционных затрат.
\end{abstract}

Ключевые слова: Ствол, угольный пласт, боковой ствол, параллельные конструкции, концентрические конструкции, траектория, осложнение.

\section{THE CURRENT STATE OF KNOWLEDGE OF DRILLING DIRECTIONAL AND MULTI-HOLE WELLS WITH SEPARATE OPERATION OF SEVERAL HORIZONS AT THE SAME TIME (FOREIGN EXPERIENCE)}

\section{Deryayev Annaguly Rejepovich}

\begin{abstract}
The economic effect of the introduction of the technology of simultaneous separate operation by drilling directional wells is expressed by reducing the cost of drilling additional wells, and also makes it possible to reduce the payback period of investments and reduce operating costs.

Key words: Trunk, coal seam, lateral trunk, parallel structures, concentric structures, trajectory, complication.

Опыт бурения скважин различного назначения позволяет сформулировать основные задачи, решаемые с применением методов, технологии и технических средств направленного бурения.
\end{abstract}


Повышение объема и качества геологической информации.

- уточнение формы геологических структур, часто очень разветвленных, и границ рудного тела путем бурения дополнительных стволов различной протяженности (от нескольких метров до нескольких сотен метров);

- определение и уточнение элементов залегания горных пород, рудных залежей методами направленного бурения и кернометрии;

- управление траекториями стволов скважин при любой их пространственной ориентации (вертикальные, горизонтальные, восстающие), в том числе при пересечении рудных залежей с заданным углом встречи.

Сокращение затрат на геологическую разведку месторождения;

- многократное пересечение рудных тел многоствольными скважинами вместо одноствольных;

- отбор технологических проб полезного ископаемого большого объема путем бурения многоствольных скважин в пределах рудного тела;

- поиск “слепых" рудных тел дополнительными стволами в сочетании с методами скважинной геофизики;

- применение более скоростного и менее затратного бескернового способа бурения шарошечными вместо колонковыми для разведки месторождений с последующим пересечением рудных тел, наличие и вертикальные границы которых надежно определяются методами скважинной геофизики;

- применение кустового бурения скважин в случаях значительных затруднений по сооружению отдельных буровых площадок и коммуникаций (болотистая или горная местность, бурение под акваторию шельфа).

Борьба с осложнениями при разведке месторождений;

- вывод скважины в заданный проектом интервал при ее значительном естественном искривлении путем корректировки траектории скважины отклонителями;

- повторное пересечение рудной залежи при ее пропуске или неудовлетворительном выходе керна;

- обход мест сложных аварий в скважине дополнительным стволом.

Облегчение условий бурения скважин: 
- снижение интенсивности естественного искривления путем применения технических средств и технологий стабилизации направления скважины;

- вывод скважин в проектную точку путем анализа, обработки и использования на этапе проектирования скважин данных о закономерностях естественного искривления скважин;

- бурение вертикально-наклонных скважин с целью улучшения условий проведения спускоподъемных операций по сравнению с наклонно забуренными скважинами, а также в случаях, когда заложение наклонной скважины невозможно по техническим характеристикам буровой установки (вращатель роторного типа, вертикально устанавливаемая буровая вышка) и получения, тем не менее, нужного угла встречи с рудной залежью;

- сокращение объема бурения скважин в сложных горногеологических условиях (поглощения, обвалы стенок и других) за счет бурения взамен ряда одноствольных скважин одной многоствольной, основной ствол которой пересекает зону осложнений, а дополнительные стволы бурятся на более глубоких горизонтах уже в более благоприятных горно-геологических условиях.

Бурение технических скважин;

- бурение вертикально-горизонтальных скважин на угольных пластах с целью их дегазации;

- бурение боковых наклонных скважин для ликвидации пожаров в скважинах, буримых с целью разведки или эксплуатации месторождений углеводородного сырья, тушения возгораний торфяников, мест складирования лигнина и других возгораемых промышленных отходов [1].

Бурение вертикально-горизонтальных, разветвленных сложно профильных эксплуатационных скважин с расположением горизонтальных и сложно профильных участков ствола в пределах нефтегазоносных коллекторов для повышения нефтегазоотдачи и дебита.

Существует большое количество видов наклонно-направленных скважин, и каждая из них имеет конфигурацию, которая может быть сложной и сильно отличаться от конфигурации других (Рис. 1): начиная со стандартных наклонных и S-образных стволов, до наклонных стволов, которые бурят с объектов, также имеющих наклон, и различных видов горизонтальных одиночных скважин и кустов. Помимо угла наклона, направление, в котором бурят скважину, также может отличаться; 
следовательно, наклонно-направленная скважина может иметь несколько различных форм. Каждая из форм соответствует определенным эксплуатационным требованиям. Более того, в процессе бурения, на основании информации, предоставляемой инженеру по бурению, может изменяться как угол наклона, так и направление бурения; таким образом, возможно и вполне реально говорить о «навигационном бурении» [2].

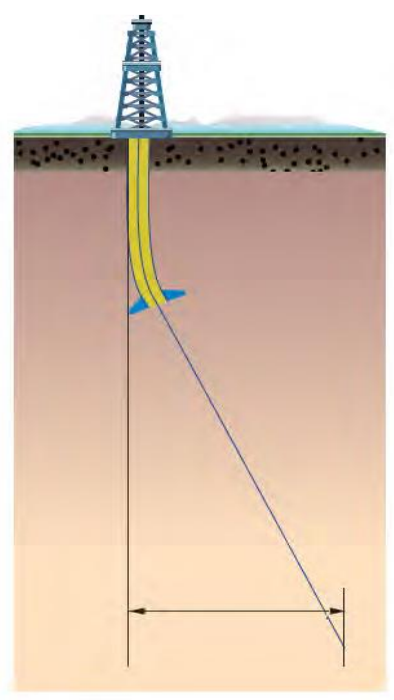

Наклонный ствол

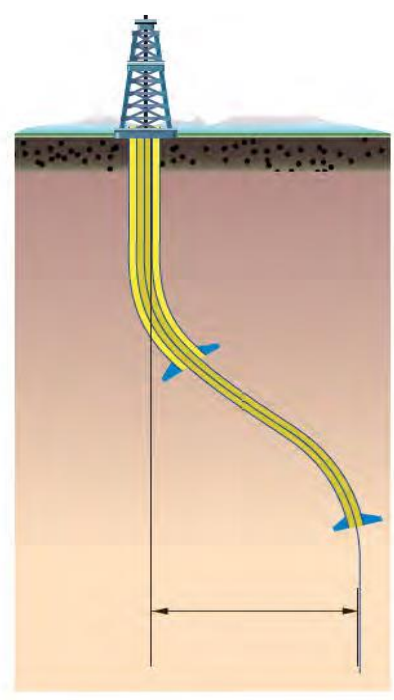

S-образный ствол

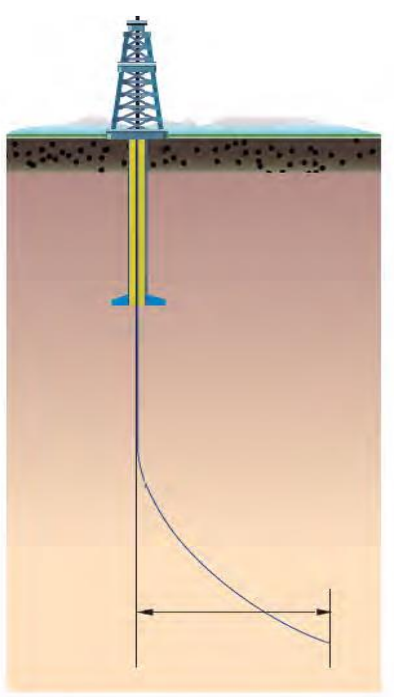

Наклонный глубокий ствол

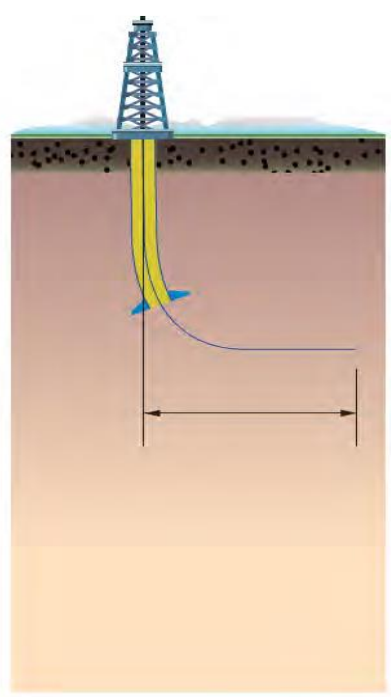

Горизонтальный ствол

\section{Рис. 1. Основные виды конфигурации наклонно-направленных скважин}

Таким образом, благодаря существующим сегодня современным технологиям, ствол скважины может иметь сложные, даже трехмерные формы, а управлять процессом бурения можно любым наиболее приемлемым способом.

Горизонтальные скважины стали бурить гораздо позднее, и их появление позволило одновременно увеличить продуктивность одиночных скважин и снизить операционные расходы на разработку отдельно взятого месторождения, а также снизить негативное влияние на окружающую среду. В реальности, горизонтальная скважина может стоить на 20\%, а то и в 2-3 раза дороже, по сравнению с вертикальной или наклонной скважиной, но ее продуктивность будет от 2-10 раз выше. Следовательно, для разработки месторождения потребуется меньшее количество скважин, и их эффективность будет прослеживаться как в отношении общей стоимости, так 
и в плане снижения влияния на окружающую среду. Это ни в коем случае не означает, что наклонно-направленная, или более того, горизонтальная скважина является наилучшим решением в любых условиях эксплуатации (положительные факторы всегда сопоставляются с отрицательными, особенно в плане устойчивости ствола, скорости проходки, ограничений продуктивности и т. д.). Но, несомненно, то, что имеющиеся сегодня технологии имеют тенденции на приоритетный выбор наклоннонаправленного и горизонтального бурения в противовес вертикальным скважинам, особенно при бурении скважин в процессе разработки месторождения. Технология вертикального бурения по-прежнему наиболее часто используется при бурении разведочных скважин. Первые попытки бурения горизонтальных скважин относятся к началу двадцатого столетия. Однако широкое распространение горизонтальное бурение получило только 80-х годах двадцатого столетия. После нескольких попыток, предпринятых в Северной Америке и Европе (бывший СССР, Франция, Северное море), бурение горизонтальных скважин стало настолько обычным в последующие годы, что стало считаться установившейся практикой, применяемой там, где позволяют условия.

Существует несколько типов горизонтальных скважин, используемых при бурении. Схематично горизонтальные скважины можно разделить на три основных типа согласно угловому градиенту, согласно значению, которого достигается горизонтальная секция. Это скважины с большим, средним и малым диаметрами. Для бурения скважин большого диаметра используются стандартные технологии бурения наклонно-направленных скважин. Темп набора кривизны может составлять 3-8 ${ }^{\circ}$ каждые 30 метров, при этом могут быть использованы от 2 до 3 секций. В первой секции достигаемый угол составляет около 40-50 и потом поддерживается неизменным на всю длину второй секции, которая может иметь значительные размеры, и лишь потом начинается третья секция. В третьей секции достигается угол до $90^{\circ}$. На этом этапе горизонтальная секция считается завершенной и может занимать достаточно большое расстояние (более 1500-2000 м и до 6000-7000 м). Существует несколько примеров скважин, которые были пробурены горизонтально и со смещением от 8000 до 10000 м. Например, «Wytch Farm M-16Z» в Великобритании, которая имеет смещение в 10727 м. Многие эксперты в области бурения заявляют, что в ближайшие годы станет 
возможным достичь смещения на расстояние до 20 миль, т. е. более чем на 30 км [3].

Для бурения скважин среднего диаметра все еще используется стандартное оборудование, хотя его и стараются модифицировать, чтобы преодолеть появляющиеся при горизонтальном бурении трудности. По сравнению с предыдущим случаем темп набора кривизны значительно увеличивается (от $8^{\circ}$ до $20^{\circ}$ каждые 30 м), хотя в теории, возможно, получить угол и в $50^{\circ}$ каждые 30 м. Длина горизонтальной секции может достигать более 1000 м, а диаметр отверстия может иметь те же значения, что имеют обычные скважины или скважины большого диаметра.

При бурении скважин малого диаметра, технологии делают возможным достижения темп набора кривизны от $30^{\circ}$ до $60^{\circ}$ на каждый метр, и поэтому становится возможным перейти к горизонтальной секции менее, чем за 3 м. Боковые стволы длиной до 300 м являются типичными для этого вида конфигураций скважин и поэтому возможно прохождение через пласты породы, чья толщина составляет всего несколько метров. Однако в этом случае приходится прибегать к помощи специального оборудования, которое сочетает в себе и особенности роторного бурения и технологии, разработанные специально для бурения скважин малого диаметра. Например, можно использовать забойные двигатели, используя короткие, тонкие секции, которые могут с легкостью проходить через изогнутую часть скважины, или для их изготовления могут использоваться материалы с низким модулем упругости на основе алюминиевых сплавов. Также, еще одним вариантом является использование труб с шарнирными соединениями. Очень часто приходится бурить более одного горизонтального ствола (именуемого «Дренаж) от одной и той же вертикальной части скважины, чтобы охватить большую часть пластового резервуара. Многоствольные скважины являются вариацией перечисленных конфигураций и состоят из нескольких горизонтальных скважин, которые берут свое начало из одной и той же вертикальной скважины. Форма этих скважин зависит от конкретной ситуации и результата, которого надо достичь (Рис. 2). Существуют боковые скважины, которые бурятся в противоположные стороны по отношению друг к другу (Рис. 2 А) и которые оказываются особенно подходящими для добычи на больших глубинах. Также целью является снижение затрат, ввиду того, что 
информация, собранная при бурении первой боковой скважины, может быть использована для оптимизации процесса бурения второй скважины, так как породы имеют схожие характеристики. Более того, возможно бурение скважин в одном направлении, но на разной глубине (Рис. 2 В). Такое решение предпочтительно, когда задачей является добыча на уровнях с разной минерализацией, как это часто случается, например, в Канаде, когда производится добыча из месторождения тяжелой нефти. Также горизонтальные скважины были пробурены «веером» или «елочкой» (например, в бассейне реки Ориноко в Венесуэле), где боковые скважины в свою очередь имели другие боковые скважины с меньшим диаметром и меньшей длиной (Рис. 2 С). Многоствольные скважины могут быть пробурены как на малой глубине (250 м), так и на большой (>5000 м), а также на месторождениях любого типа: легкой нефти или тяжелой, или газовых месторождениях. К одной скважине с горизонтальной секцией, которая может иметь в длину 1300-1500 м и залегать на глубине 5300-5500 м, возможно, нарастить до 4 горизонтальных скважин [4].

На основании вышеизложенного становится очевидно, что в настоящее время бурение даже самых сложных наклонно-направленных и горизонтальных скважин сопровождается разнообразными технологиями, которые не стоят на месте и продолжают совершенствоваться. Благодаря этому данные технологии могут использоваться в любых ситуациях, независимо от их сложности и предъявляемых требований. Кроме того, становится известно, что бурение, в особенности горизонтальных скважин с большим отходом, измеряемым несколькими километрами, имеет неоспоримые преимущества не только в плане потенциала добычи каждой скважины, который можно значительно повысить в сравнении $\mathrm{c}$ вертикальными и традиционными наклонными скважинами, но и в плане затрат на разработку месторождения, а также с точки зрения экологии. 


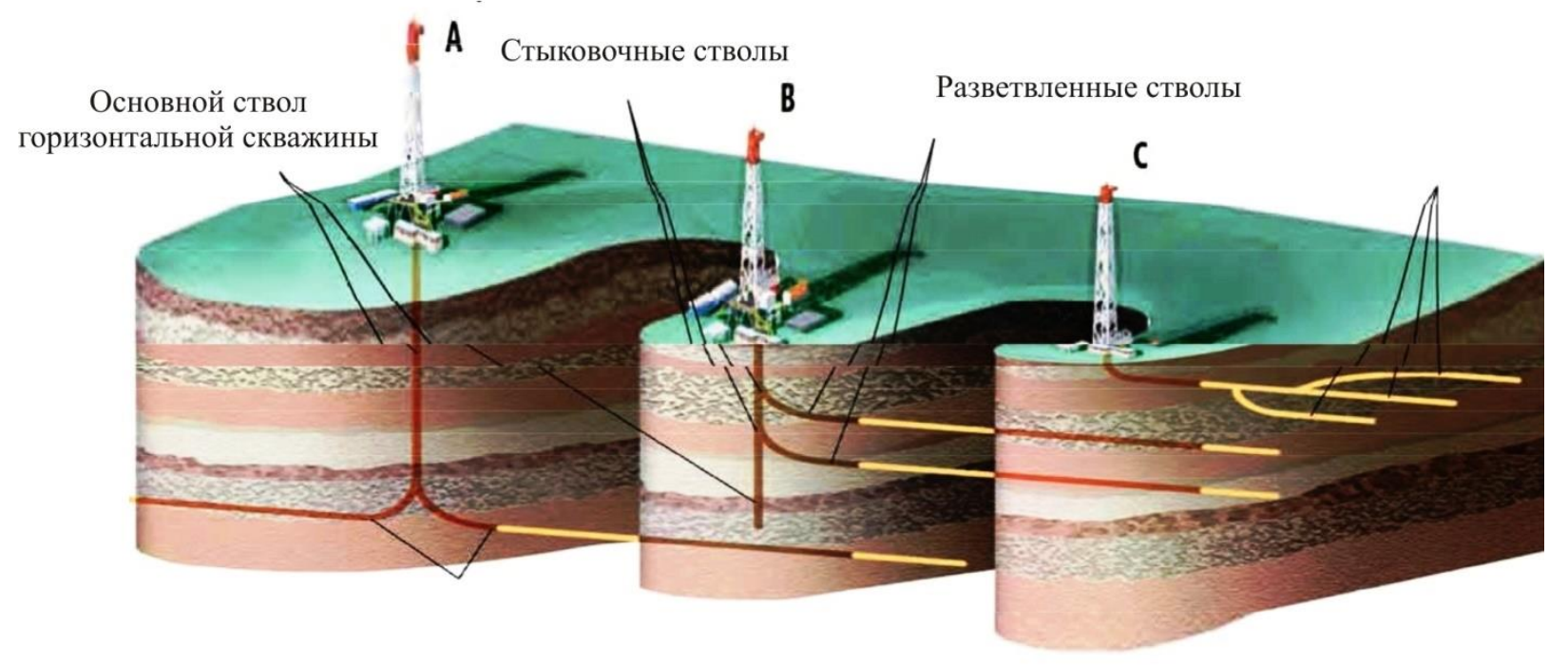

Боковые стволы противоположной направленности
Пласты с низкой проницаемостью или естественными разломами

\section{Рис. 2. Виды многоствольных} горизонтальных скважин

Нормативные акты в ряде стран, особенно в США, требуют при разработке нефтяных месторождений в первую очередь бурения наклоннонаправленных и горизонтальных скважин, прежде всего с целью снижения влияния работ на окружающую среду (Рис. 3).

Меньше скважин, к тому же расположенных на большом расстоянии от экологически уязвимых и охраняемых территорий, приводит к значительному сокращению объемов инфраструктуры, необходимой для разработки и обеспечения эксплуатации месторождения, например, буровых площадок, подъездных дорог, стоянок, транспортных средств. 

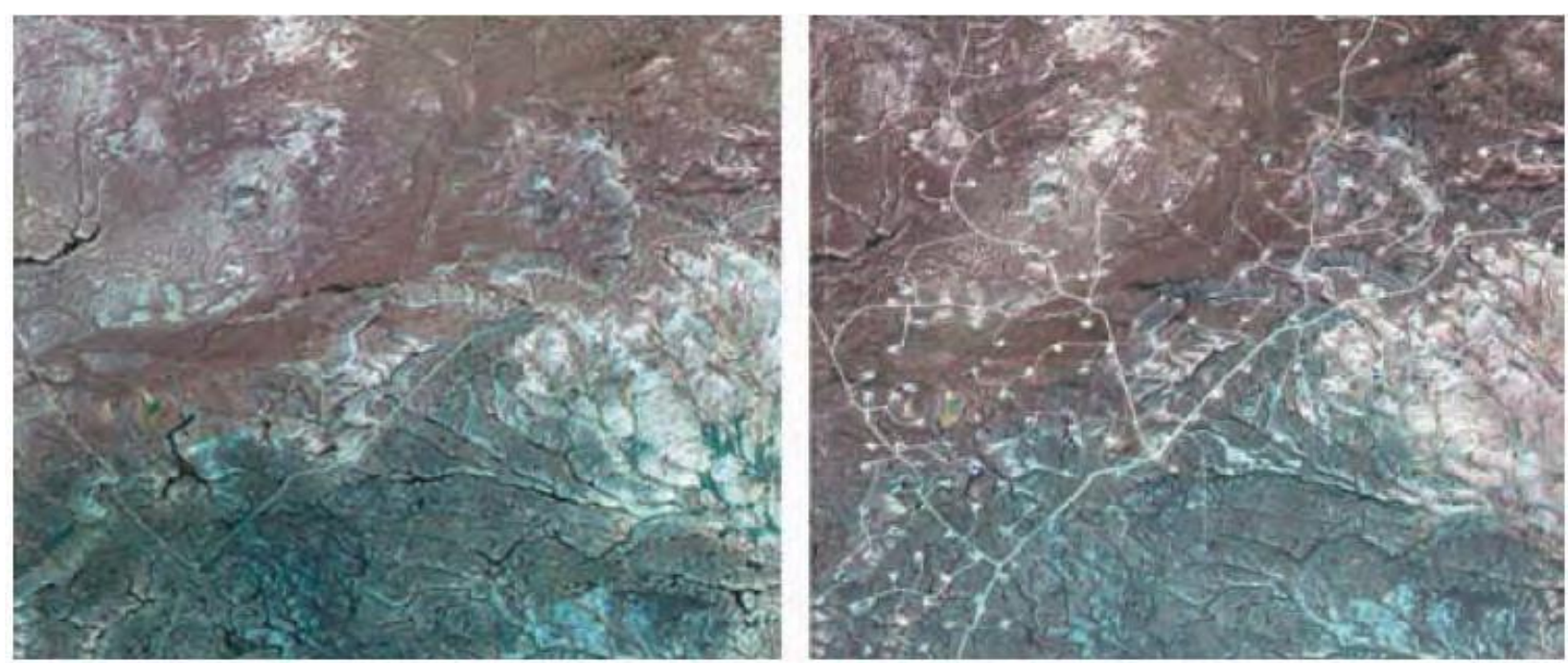

Рис. 3. Фотографии месторождения Джона Филд, Вайоминг, США, сделанные спутником «Ландсат» в разные моменты его эксплуатации: так месторождение, выглядело 27 августа 1986 года до начала его разработки (слева) и 18 октября 2002 года после бурения около 400 скважин (справа)

Бурение горизонтальных скважин могло бы значительно снизить возникшие в результате экологические последствия (SkyTruth). Bсе это снижает экологическую нагрузку на территорию и дает огромные преимущества в плане сохранения окружающей среды.

\section{Список литературы}

1. Буглов Н. А. Влияние технико-технологических факторов на интенсивность искрывления геологоразведочных скважин. Геология и разведка; сборник научных трудов выпуск 11. 1986г.

2. Зиненко В.П. Направленное бурение: учебное пособие для вузов/ В.П. Зиненко - Москва Недра, 1990 г.

3. Калинин А.Г., Разведочное бурение: учебник для горногеологических вузов/ А.Г.Калинин, О.В. Ошкордин, В.М. Питерский, Н.В. Соловьев. - Москва., “Недра-Бизнесцентр”, 2000г.

4. Костин Ю.С. Современные методы направленного бурения скважин/ Ю.С. Костин- Москва. Недра, 1982г. 